\title{
Green Infrastructure and Manufacturing: Analysis of IE and SM Innovations for Future Generations
}

\author{
Bukuroshe Elira \\ Epoka University, Autostrada Tiranë-Rinas, km. 12, 1000, Albania \\ Eliraepoka230@hotmail.com
}

\begin{abstract}
ArticleInfo
Journal of Machine and Computing (http://anapub.co.ke/journals/jmc/jmc.html)

Doi : https://doi.org/10.53759/7669/jmc202101011

Received 25 December 2020; Revised form 30 January 2021; Accepted 26 March 2021; Available online 05 April 2021.

(C)2021 The Authors. Published by AnaPub Publications.

This is an open access article under the CC BY-NC-ND license. (http://creativecommons.org/licenses/by-nc-nd/4.0/)

Abstract - This paper focusses on SM, which is an innovation for the future generation of industries. In manufacturing, Sustainable Manufacturing (SM) is a significant aspect that deals with the functioning, designing, productivity, profitability and competitiveness. It is considered that future ecological and better ecological performance practices will base more in designs and manufacturing priorities for enhancing manufacturing developments and advancements. Decision makers, manufacturers and designers who have to practice more and launch sustainable cultures in industries will basically remain successful in their segments since there are a major necessity of the modern age and the future. Moreover, extensive research and analysis is require to future improve and enhance the comprehension of better ecological performance in industrial manufacturing.
\end{abstract}

Keyword - Industrial Ecology (IE), Sustainable Manufacturing (SM), Greenhouse Gas (GHG)

\section{INTRODUCTION}

Industrial Ecology (IE) applies the processes and structures of natural ecosystem for managing activities across different domains of information exchange, ecological quality, energy and material domains [1]. IE focusses on the concept of better ecological performance that indicates the integrated (composite) development whereas consuming the least available resources and minimizing effluence of air, water and land. Better ecological performance promotes global approach and systematic scheme to minimize the consumption of resources, decarbonize power, and deal with Greenhouse Gas (GHG) emission, including the encouragement of recyclability of materials. The focus on reuse and recycling in manufacturing processes minimize the requirement for the extraction of raw materials and the disposal of wastes. This strives to fundamentally encourage the usage of renewable energy with lower emission of carbon and GHG.

Tools of sustainable engineering incorporate the assessment of life cycle, flow of materials. output/input economic framework, and the indicators for assessing and measuring better ecological performance. In reference to ISO 140-40 standard, LCA shall incorporate four different stages and they are scope and goal definition, inventory evaluation, impact evaluation and interpretation of findings. Based on IE, knowledge on how to modify, reuse and recycle materials is obtained. This is projected to save money for the biomaterials and minimize GHG emission and the consumption of energy [2]. The mission for mechanical engineers has to consider the design tasks e.g. managing reuse and recycling of products at the end of the lifecycle. Targets have to be towards the creation of intricately efficient and networked design for disposal activities. The most fundamental aspect for IE is energy and material balancing. Material balancing is critical to manufacturing control, basically in the control of product yields.

The balancing of energy is applicable in the assessment of different process stages, over the complete production procedure and even in the extension of the general production scheme from raw materials to finished products and even disposal. Process flow may be structured stepwise i.e. through the identification of wastes, output and inputs at every process stage. In the process, the operating procedure parameter e.g. pressure, temperature, and percentage parameters should be incorporated. Energy and material balancing can be complicated at different stages, but the major approach is considered straightforward.

The advancing application of computers stimulates energy balance model and mass models that are manipulated easily and applied in production management in an aim to minimize costs and production. Carbon footprints can be evaluated with respect to the overall power of embodied energy including the processing energies in manufacturing procedures [3]. The balances are also significant for evaluating the advancements made in the progressive projects whereas assessing cost benefits. 
The stages in energy and mass balancing calculations determine if energy and mass flows have been assessed directly or indirectly. These have to agree with the conversions of energy and mass principles. A step-by-step methodology is advocated as:

- Step 1: Significantly identifying the issue to be assessed. In the case of manufacturing scheme issues, we need to identify the material elimination procedure e.g. grinding, milling and turning since they operate based on various rules and the mechanics of material elimination vary.

- Step 2: Define the boundaries, which enclose the complete scheme or equipment to be evaluated

- Step 3: The enclosing boundaries are such that measurement is considered easy and accurate

- $\quad$ Step 4: Choose the most effective test period based on the forms of products and processes. Evaluate energy and the flow of mass with respect to the measurements in step 3 and step 5.

- Step 5: Determine the energy and mass balance. In case balances are outside the acknowledged limits, then repeat measurements.

- Step 6: The release of energy and usage in exothermic and endothermic processes have to be considered in the balancing of energy.

Poor thermodynamic performances are mostly the result of power loss in heat transfer and combustion. In that case, there is the need to energy, mass and heat balance research in thermodynamics. The aspect of better ecological performance reflects on the necessity to accomplish the current needs without affecting the capacity of the future generations to accomplish their own needs. In the wide scope application of the concept, better ecological performance has led to the advancing identification of three fundamental aspects of sustainable enhancement that include social, ecological and economical aspects as shown in Fig 1 below.

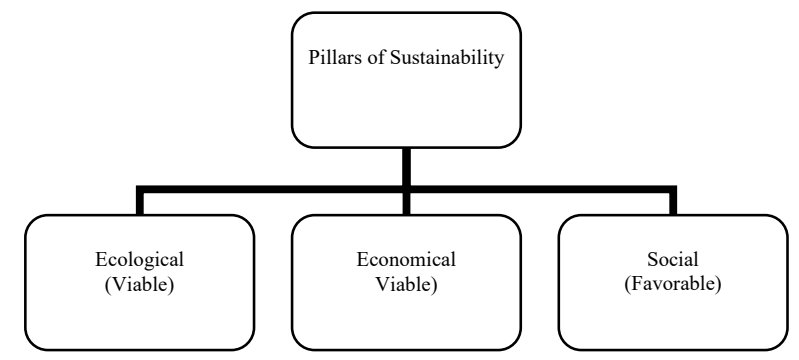

Fig 1: Pillars of better ecological performance bounded by the ecosystem

Traditionally, the aspect of manufacturing has been linked to the undesirable ecosystem side effects since producers and manufacturers are obliged for the changes of resource application into fundamental output, i.e. engineered products that are of value economically, with efficiency or limit because of thermodynamics laws. Over the past few decades, the ecological burden connected to industrial activities has not become significantly fundamental hence attracting the attention of global manufacturers and the community. Academia and manufacturers have been concerned about the implications of human activities on the ecosystem, which promote the application of ecological degradation and prevention practices.

These ecological practices can be found under different labels and IE segments, life cycle of products and management schemes, corporate environmental management schemes, supply chain management schemes, design of ecological, and product/service schemes. There are various factors playing a fundamental role in explaining the necessities of the upcoming generation manufacturing paradigm, e.g. enhancing system or product complexity, ecological concern, lack of skill integration, high-tech advancements in simulation and modelling techniques.

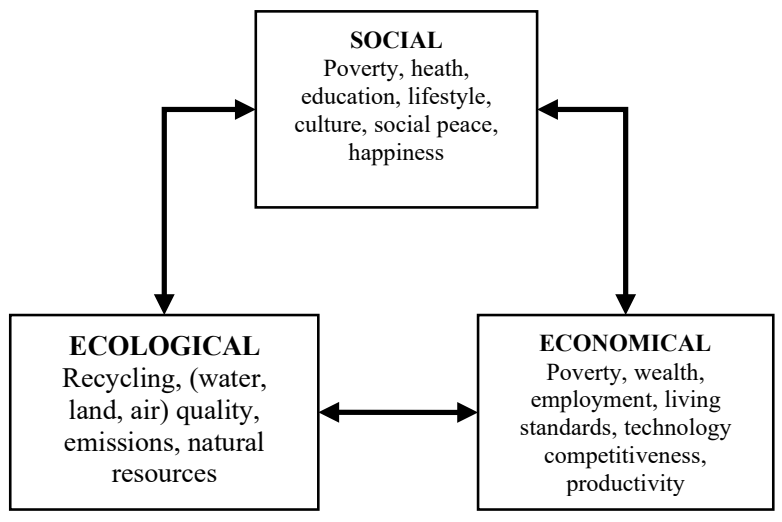

Fig 2: Connections between economic, ecological and social aspects of better ecological performance, and factors influencing them 
Over the past few decades, the Sustainable Manufacturing (SM) concept has been structured under different labels such as Green Manufacturing, and Ecologically Conscious Manufacturing as a concept of preventing effluence. The major purpose of SM is to minimize the ecological implication connected to manufacturing. Ecological activities have widely been connected with the negative implications on business performance; however, this assumption has been considered untrue by B. Janik in [4]. The indicators of better ecological performance among various factors that influence them have been shown in Fig 2 below.

This section has introduced the concept of IE and SM. The balancing of energy has been seen to be applicable in the assessment of different process stages, over the complete production procedure and even in the extension. Section 1 has mentioned the stages of mass and energy balancing for ensuring SM. The remaining section addresses the significance of IE and SM and its innovations for future generations. The paper has been organized as follows: Section II discussed the background analysis of the research. Section III is the literature review part. Section IV presents a critical analysis of the IE and SM for future generations. Section V is the conclusion section, which also presents future directions.

\section{BACKGROUND ANALYSIS}

This research contribution focusses on IE and SM as innovations for future generations. It is basically recognized that fluid mechanics and thermodynamics are challenging and complex fields for researchers and mechanical engineers. For engineers, these aspects are further evaluated in fluid and thermal mechanics laboratories and are further simulated using advanced Computer Aided Engineering labs. Engineering systems in manufacturing and design have to follow rigorous thermodynamic definition of systems.

Better ecological performance method focusses on the identification of how far from the surrounding (vs equilibrium) processes and outcomes are at any aspect of lifecycle. At the end of the significant life, it gets back to the ecosystem and it begins its journey with roots from extraction. This has been conceived to consider systems as closed schemes other than open systems and the various thermodynamic features of energy and entropy generations have to be applied to enhance better ecological performance. Humans can effectively apply thermodynamics by concentrating on bio-physical resources and utilizing aggregate measurement of the second law on resource conversion.

Engineers in various fields have focused on enhancing better ecological performance and have used the concept of thermodynamics. Energy balancing and mass balancing has to be considered in various engineering fields to account for the initiative of better ecological performance. Tools (Jha) are utilized in the diversification of materials and processing of operations, e.g. machining, forging procedures, heat treatment, phase change procedures and diffusion among others.

For this research, SM signifies a concept for sustainable enhancement, which emerged in the early 80 s and attracted the attention of engineers concerning ecological implications of economic development and global enhancement of business and trade. Sustainable development signifies the development that fulfills the requirements of the current without necessarily affecting the capability of the future generations to fulfill their own needs.

In this research, manufacturing better ecological performance and its need for the future generation has been assessed. Manufacturing industrials account for fundamental segments of the globes consumption of raw materials and waste generation. Globally, the consumption of energy of manufacturing firms advanced to 60\% from 1969-2004. This advancement was about a third of today's energy usage.

This paper has extensively focused on innovation aspect of SM. In this case, significant attention has been paid regarding the innovations embraced in the past. These innovations are critical for firms and policy makers to effective embrace system developments in practices, performances, and corporate environments. Eco-innovation dimension has also been appreciated in this research and this incorporates dimensions such as impacts, mechanisms and target.

\section{LITERATURE REVIEW}

Y. Matsuyama, S. Fukushige and Y. Umeda in [5] stress that engineers have to comprehend the complete life cycles, systems and the end of life application of products and these have also been stressed out by the Academia. This ideology of comprehension is in consistent with the objectives from the National Science Foundation (NSF), which also incorporate the requirements from the American Society of Mechanical Engineering (ASME). It is fundamental to transform the literature assumptions to communicating and recognizing epic condition of better ecological performance discourse and this incorporate SM.

B. Sørensen in [6] comments that less attention has been put on life cycle evaluation, renewable energy concepts, and approaches of waste minimization. In that case, engineering institutions presently accredit engineering education programs and identify the need for the topics to be addressed. Engineering and Technology Accreditation Board has placed the requirement for program assessment and outcomes identifying that other than knowledge in problem-solving, engineering principles and science, engineers have to possess knowledge to: operate on multidisciplinary groups, communicate in an effective manner, and comprehend ethical and professional responsibility.

R. Bhattacharjee, M. Chakraborty and L. Choudhury in [7] presented a Venn diagram to illustrate better ecological performance that assures economic development and ecological balance alongside equitability of the community and economic enhancement. Developing better ecological performance of manufactured engineering products is fundamental matter for the future generation of engineers. It would amount in the minimization of disposal charges, minimization of 
effluence and lastly fewer issues in the community. The aspect of recycling and disassembly has to be incorporated in the designing of products.

C. Boks and E. Tempelman in [8] agree that recycling and disassembly would help significantly in the minimization of toxic and harmful emissions to the ecosystem hence affective global warming, and guaranteeing better ecological performance. According to F. Tonkaboni in [9], institutions have to advance certain goals in engineering curriculum to ascertain a sustainable future ahead: minimize the usage of resources e.g. water, energy and materials; minimize harmful or otherwise toxic emissions to the ecosystem influencing global warming; enhance the management of renewable resource to facilitate better ecological performance.

O. Gjørv in [10] agrees that durability and quality of products will be replaced more frequently, minimizing the requirement of materials for the future generations. J. Walters in [11] has also agreed that recycling and reuse, with the consideration of mechanical engineering designing tools. Design for the environment has to be a fundamental element of mechanical designing and this has to incorporate ASME requirements. Extrinsic characteristics alongside embodied energy, emissions of GHG, and costs have to be incorporate in the designing process.

T. Dzhuguryan and A. Deja in [12] argue that institutions have to incorporate course on the Manufacturing and Designing of Better ecological performance (MDS) or Green Designing and Manufacturing for SM (GDMS) to equip future engineers with fundamental knowledge on IE and sustainable development. These are the courses that present traceable data that are fundamental to product engineers and manufacturing designers to enhance the incorporation of better ecological performance in their careers and comply with global regulations.

Y. He, T. Kvan, M. Liu and B. Li in [13] confirm that green designing and design for the environment has the major purpose of minimizing waste of materials and the emission of greenhouse gas into the atmosphere. Curriculum to be developed by institutions focus on the overall life cycle of products from grave-to-gate or grave-to-grave. Some fundamental aspect of the designing process for the ecosystem include; manufacture without emitting hazardous wastes; utility of clean technology, minimization of product chemical emission, minimization of the consumption of product energy; utility of hazardous recyclable material; usage of recycled materials and reused components; designing for use of disassembly product reuse or end of life recycling.

C. Herrmann, M. Hauschild, T. Gutowski and R. Lifset in [14] agree that institutions of engineering should put more emphasis on developments to build future engineers for SM and IE. A. Choi and P. Guda in [15] recommend the design for assembly to enhance the percentage of reuse and recycling. In the design stage, fundamental steps have to be followed. Minimizing the number of components or parts in the assembly make it easier to assemble and manufacture. Fundamental materials will also influence the costs of assembly. Even though other researchers have presented slight variation in detail, concentrating on the issue of IE and SM is fundamental for this contribution.

For SM and IE for future generation, material diversity should generally be minimized, eliminate the usage of laminates or develop them to be compatible materials that can be recycle as a mixture. In addition, fastener should be applied to minimize the diversity and count; eliminate incompatible adhesives that degrade material recyclability; utilize snap fitting where effective. Component designing issues such as eliminating laminates and paints should be considered; develop in plane for easier access and separation. Section IV below presents a critical analysis of SM and IE, which are developments to be applied for future generations.

\section{CRITICAL ANALYSIS}

\section{A. $S M$}

SM is a concept for sustainable development that emerged in the early 1980s and raised concern and awareness over the ecological implication of economic development and global development of trade and business. Sustainable development represent the enhancement that meets the needs of the current without affective the ability of the upcoming generation to accomplish their individual needs. SM is viewed based on two concepts. The first one is the concept of needs, particularly the fundamental needs of the globes poor, while overriding the major priorities being considered. The second concept is the ideology of limitations that have been imposed by the high-tech status and social structure of the ecological capacity to accomplish the present and future needs.

Manufacturing systems, mass and energy systems have to balance with outputs of energy and mass. Thus, the conservation laws of mass leads to the equation of material balancing.

Mass stored + mass out, raw materials $=$ Mass in $=$ Stored materials + wastes + products

Raw materials:

$$
\sum m_{R}=\sum m_{R 1}+\sum m_{R 2}+\sum m_{R 3}
$$

Products:

$$
\sum m_{p}=\sum m_{p 1}+\sum m_{p 2}+\sum m_{p 3}
$$


Wastes

$$
\sum m_{w}=\sum m_{w 1}+\sum m_{w 2}+\sum m_{w 3}
$$

Stored

$$
\sum m_{s}=\sum m_{s 1}+\sum m_{s 2}+\sum m_{s 3}
$$

Mass stored + mass out, raw materials $=$ Mass in $=$ Stored materials + wastes + products

It is possible that in manufacturing schemes more than a single product is manufactured: $\mathrm{Pm}=1,2,3, \ldots . \mathrm{n}$. In this case, 3 products have been indicated for illustration. Energy input represents the embodied energy for different materials and product. Waste materials in the schemes of manufacturing (certainly machining) are chips being formed after machining. We require energy during the process of machining and should be incorporated in the equation of energy balance. Energy and mass both follow the conservation principle. The embodied energy into the operations and energy utilized for manufacturing has to balance energy stored and energy coming out.

In the UNCED conference held in 1992 at Rio de Janeiro, SM was adopted as one of the governing principles for governments and businesses in changing and accomplishing sustainable enhancement [16]. Better ecological performance is gradually becoming a projected business practice by industries, whether small or large. Manufacturing industries and their network of distributors and customers are obliged for the development of SM. There are different explanations of SM according to center and department. US Commerce Department: "For the aims of commerce's SM initiatives, SM is considered as the formation of manufactured products, which utilize the procedures, which minimize negative ecological implications, conserve natural resources and energy. The Lowell Center for SM: SM is the formation of services and goods using systems and processes that are conserving natural resources and energy; non-polluting; economically viable; creatively and socially rewarding for workers; and healthful or safe for consumers, communities and workers.

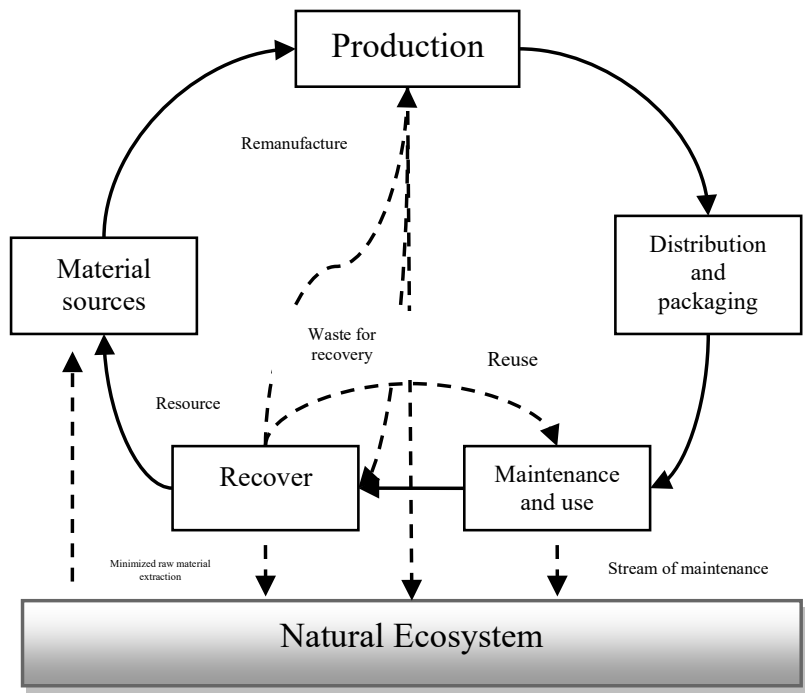

Fig 3: Closed loop manufacturing scheme

\section{B. Manufacturing Better ecological performance - Need for Future Generations}

Manufacturing firms account for fundamental segments of the consumption of raw materials and waste production internationally. Globally, energy consumption advanced by 60\% from 1969 to 2005, which represented the modern usage of energy. Similarly, they are obliged for about $35 \%$ of the global emissions of carbon dioxide. However, manufacturing industries have the capacity to become a major force for the formation of sustainable community. They can effectively formulate and apply integrated sustainable activities and structure services and products, which contribute to effective ecological performance. This necessitates a transition in the comprehension and perception of industrial production and the implementation of holistic approaches to run businesses.

Ecological implication of industrial manufacturing has historically been handled with the dispersing effluence in less apparent and harmful manner [17]. Guided in part by stringent ecological regulations, industries have been utilized in different treatments and measures meant to minimize the amount of effluents and emissions. Over the past few decades, its efforts to enhance ecological efficiency have shifted to the focus on the integrated, lifestyle ecological approaches, and management schemes. Thus, industries have started to acknowledge significant ecological responsibilities throughout the value chain. The implementation of more systematic and integrated approach to enhance better ecological performance performance has created foundation for novel organizational modes and models of provision that can possibly amount to significant ecological advantages. 
Efforts to formulate closed loop circular production schemes have certainly concentrated on revitalizing disposed products into novel resources for manufacturing (See Fig 3); for instance, by creating eco-industrial parks for ecological and economic synergies for traditionally unrelated industrial manufacturers.

According to Fig 4, how do the concepts of SM vary? SM is more detailed and systemic compared to gree, ecomachining, eco-manufacturing, clean production by handling all the three elements of better ecological performance ie community, economy and environment. Whereas it incorporates all the ecological concerns, e.g. effluence, GHG emissions, material toxicity, they are not limited to these concerns, nor are they considered the components of ecological management schemes. Sustainable mmanufacturing utilize both the technical and non-technical solutions, from the choice of materials and the processess of production to organizational missions, performance reporting and structures.

It changes the focus from the end-of-pipe remedy, waste disposal, clean-up recovery, liability method, to the start of the process and product design phase, considered as an opportunity strategy. Why is it significant? There are different fundmaental drivers for implementing SM into the industries' strategic inititiaves:

- The present global economics crisis has presented the fragility and non-viability of the present organizational models focussing on the higher economic development through mitigating and assessing the negative implicatio of exterior industrial boundaries.

- The reality of climatic transition, its anthropomorphic effects and the necessities to reverse trends before the effects on human habitat are severe.

- The pressure from all classes of stakeholders: global regulatory bodies, non-governmental organizations, national governments, communities, competitors, suppliers, workers, investors, and customers.

- Scarcity of fundamental resources for actions: water, raw materials, energy and prices volatility by advancing the competition for cost extraction of diminishing virgin materials and non-renewable resources.

Control of effluence

Ecofriendly
Lifecycle brainstorm
Close loop
manufacturing

Industrial ecology

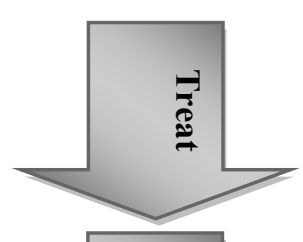

$\frac{\text { Application of non-fundamental technology }}{\text { (End-of-the-pipe remedies) }}$

Modification of products and production techniques (Procedure optimization, low resource output and input material resources; renewable and non-toxic materials)

Systematic ecological control

(Ecological methods and monitoring ecological management schemes)

Extending ecological responsibilities

(Green supply chain control, corporate social responsibility)

\section{$\underline{\text { Restructuring of production approaches }}$}

Eliminating and minimizing raw materials

Incorporate schemes of production

Eco-industrial components

Ecological partnership

Fig 4: Transformation of SM practices and concepts 


\section{Innovation}

Significant attention has over the past few decades, been concentrated on advancements for firms and policy makers to attain systemic advancement in corporate environmental performances and practice. Most firms have started to use ecoinitiatives to illustrate their contribution to sustainability. Governments are now promoting the concept to attain targets for maintainability and targets while maintaining the industry and competition. Nonetheless, whereas the promotion of ecoinnovation of the government and the industry incorporates pursuit of both ecological and economic better ecological performance, the application and scope of concepts tend to be different.

Eco-initiatives concentrate on supporting objectives for Lisbon approaches for competitiveness and economic developments. The idea of enhancing 'Ecological Technology Action Plan' describes eco-initiatives as the assimilation, exploitation and production of newly formed production processes, products, services in management and organizational approaches throughout its lifecycle to substantially prevent and reduce ecological risks, effluence and negative implication of resource utility. Ecological developments are considered to potentially promise the enhancement of ecological conditions without affecting the economic development in the US where they have been considered through different private and public partnership programs and taxing credits.

Now, the promotion of eco-innovation has concentrated significant of the ecological developments; however, there is a habit to widen the major scope of the concept. In Japan, the federation's industrial science high-tech committee for policy formulation explains eco-innovation as a novel field of high-tech and social innovation, which focusses on less products, functions, ecology and people. Eco-innovations are therefore considered as an overarching ideology that provides the vision and direction for pursuing the general community transformation required to accomplish better ecological performance development.

\section{1) Eco-innovation Dimensions}

Eco-innovation incorporates three fundamental dimensions: impacts, mechanisms and targets. OECD explains innovation as the application of novel and fundamentally enhanced products (services and goods), or procedure, a novel marketing approach, or a novel organizational approach for organizational practices, workforce organization and external relationships. Eco-innovation is fundamental the same as other forms of innovation; however, with two significant differences:

- Eco-innovation signifies the innovations resulting to the minimization of ecological impacts, irrespective of whether the effect has been attended or not.

- The overall ecope of eco-innovation may surpasss conventional organizational boundary of innovating the business and incorporating wider social arrangement, which stimulates transformation in the present socio cultural habits and organizational structures.

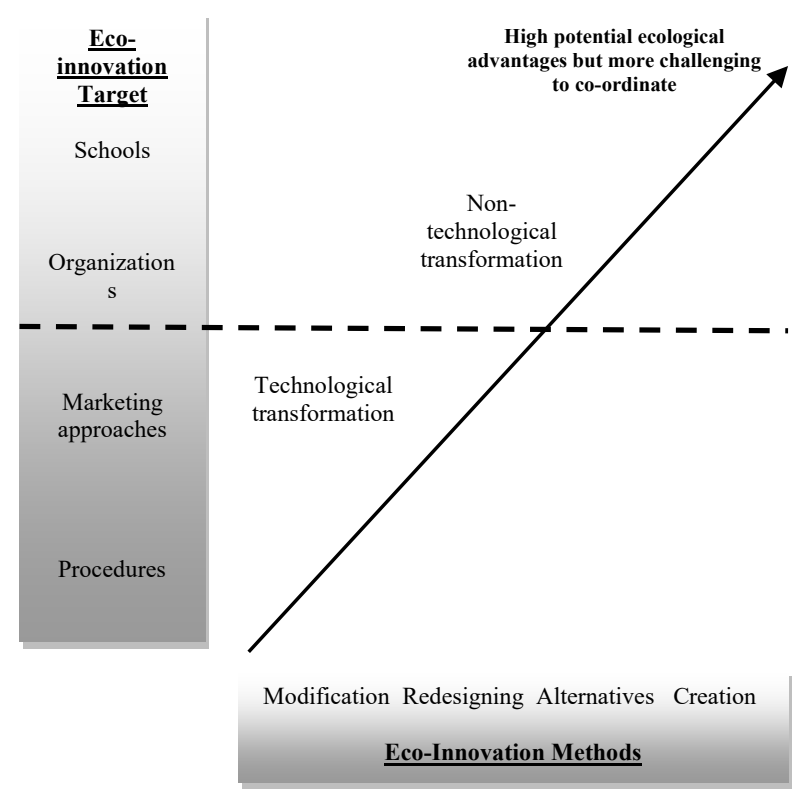

Fig 5: Major Facets of eco-innovation

a) Targets

Targets are a basic form of eco-innovation and incorporate institutiions, organizations, marketing approaches, processess and products as seen in Fig 6. Eco-innovation in processes and products tend to depend on the high-tech development whereas eco-innovation in instutions, organization and marketing depends on non-high-tech transformations. 


\section{b) Mechanisms}

Mechanisms define the manner in which transformations in the targetted segment are structured. They can incorporate practical modification, redesigning of practices, major alternatives of the present practices or the formation of novel practices.

\section{c) Impacts}

Impacts signify the manner in which eco-innovation influences the ecological factors and conditions. Experience indicates that more radical transformation in approaches, such as creation and alyernatives result in high ecological advantages.

Eco-innovation, which is multi-level, stimulates SM. Both the government and the industry have to comprehend and determine the manner in which industries should more into the future. Innovation is vital in shifting manufacturing industries towards SM. Changing sustainable production initiatives from the traditional approaches of effluence management through clean production initiatives, to lifecycle perspective, to the creation of closed-loop manufacturing, can be considered to be facilitated by eco-innovations.

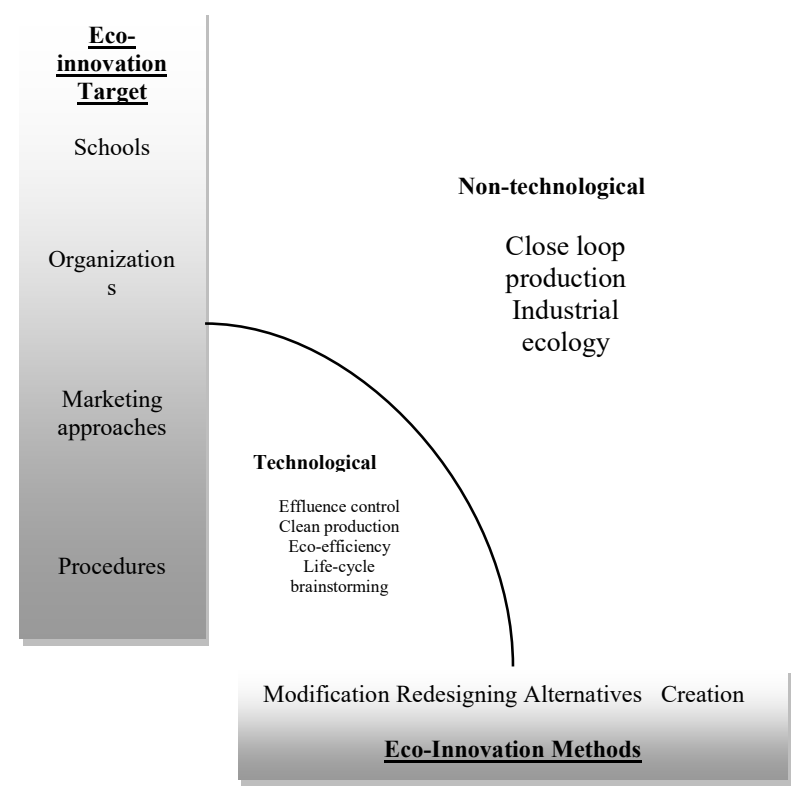

Fig 6: Concept connection between eco-innovation and SM

Fig 6 represents a basic illustration of the overall conceptual connection between eco-innovation and SM. The phases in SM are shown based on their primary connection based on eco-innovation, i.e. with the initiatives target on the left side and mechanisms below. Waves spread over the upper segment show the path dependency of various SM concepts.

The present eco-innovation concentrate significantly on high-tech advancement; however, this is facilitate through nonhigh-tech transformation. To effectively comprehend the present application of eco-initiatives in manufacturing firms, a minor sample of sector-particular examples are evaluated based on the model above. The sectors selected include Transport and automotive industry; Steel and iron industry; and electronic industry (See Table 1). These examples draw significantly on the questionnaire analysis and concentrate on group meetings done among leading firms in OECD nations as a major segment of this project. Eco-innovation is considered effective and developed based on the application of characteristics of arrays that range from the creation and modifications across products, institutions, organizations and processes [18]. 
Table 1: Eco-innovation samples evaluated in this project and association/company eco-innovation sample

\begin{tabular}{|c|c|}
\hline Company/industry association & Eco-innovation samples \\
\hline Transport and automotive industry & - $\quad$ Self service bicycle sharing scheme \\
\hline - $\quad$ Toyota & - $\quad$ Energy saving forms \\
\hline BMW group & - $\quad$ System plant \\
\hline & - $\quad$ Enhancing energy efficiency in automobile \\
\hline Steel/Iron Industry & Alternative iron making procedure \\
\hline - $\quad$ ULSAB AVC & - $\quad$ advance high-strenghth automobiles and steel \\
\hline - $\quad$ Sieners VAI & \\
\hline Electronics industry & Managed print service \\
\hline - $\quad$ Snap & - $\quad$ Enhancing recylabling of electric appliances \\
\hline BM & $\begin{array}{l}\text { - Energy saving controllers for air conditoning water } \\
\text { pumps }\end{array}$ \\
\hline & - $\quad$ Energy efficency in information centers \\
\hline
\end{tabular}

\section{CONCLUSION AND FUTURE DIRECTIONS}

In conclusion, this paper has evaluated the various aspect of the concept of better ecological performance. In this research, various definitions of SM have been provided. Different concerns based on innovations with which it relates, and its requirement in the future has been presented. Based on OECD synthesis analysis, different factors on this have been projected above. In that case, comprehensive explanation of the term has been provided to aid researchers to draw potential researches regarding SM. One of the major innovations to be considered include material diversity, which should generally be minimized, eliminate the usage of laminates or develop them to be compatible materials that can be recycle as a mixture. Moreover, fastener should be applied to minimize the diversity and count; eliminate incompatible adhesives that degrade material recyclability; utilize snap fitting where effective.

\section{References}

[1]. L. Bettencourt and C. Brelsford, "IE: The View From Complex Systems", Journal of IE, vol. 19, no. 2, pp. 195-197, 2015. Available: 10.1111/jiec. 12243 .

[2]. A. Polevoy and A. Mykytiuk, "Modelling greenhouse gas emission from organic soils (PEAT-GHG-model)", Ukrainian hydrometeorological journal, no. 16, pp. 141-148, 2017. Available: 10.31481/uhmj.16.2015.18.

[3]. B. Goldhammer, C. Busse and T. Busch, "Estimating Corporate Carbon Footprints with Externally Available Data", Journal of IE, vol. 21, no. 5, pp. 1165-1179, 2016. Available: 10.1111/jiec.12522.

[4]. B. Janik, "Ecological and eco-innovative activities of the Banks", Perspectives of Innovations, Economics and Business, vol. 16, no. 1, pp. 13-20, 2016. Available: 10.15208/pieb.2016.02.

[5]. Y. Matsuyama, S. Fukushige and Y. Umeda, "Simulating Life Cycles of Individual Products for Life Cycle Design", Procedia CIRP, vol. 38, pp. 159-164, 2015. Available: 10.1016/j.procir.2015.08.025.

[6]. B. Sørensen, "Life-cycle analysis of renewable energy systems", Renewable Energy, vol. 5, no. 5-8, pp. 1270-1277, 1994. Available: 10.1016/0960-1481(94)90161-9.

[7]. R. Bhattacharjee, M. Chakraborty and L. Choudhury, "Venn Diagram with Names of Individuals and Their Absence: A Non-classical Diagram Logic", Logica Universalis, vol. 12, no. 1-2, pp. 141-206, 2018. Available: 10.1007/s11787-018-0186-7.

[8]. C. Boks and E. Tempelman, "Future disassembly and recycling technology", Futures, vol. 30, no. 5, pp. 425-442, 1998. Available: 10.1016/s0016-3287(98)00046-9.

[9]. F. Tonkaboni, "The Impeding Factors and Strategies for Formulating University Curriculum Goals (A Social Capital Development Approach)", Management, vol. 2, no. 2, p. 1, 2018. Available: 10.31058/j.mana.2018.22006.

[10]. O. Gjørv, "Quality Control and Quality Assurance for Concrete Durability", Key Engineering Materials, vol. 711, pp. 76-83, 2016. Available: 10.4028/www.scientific.net/kem.711.76.

[11]. J. Walters, "Wastewater reuse and recycling technology", Conservation \& Recycling, vol. 9, no. 1, pp. 140-141, 1986. Available: 10.1016/03613658(86)90147-5.

[12]. T. Dzhuguryan and A. Deja, "Sustainable Waste Management for a City Multifloor Manufacturing Cluster: A Framework for Designing a Smart Supply Chain", Better ecological performance, vol. 13, no. 3, p. 1540, 2021. Available: 10.3390/su13031540.

[13]. Y. He, T. Kvan, M. Liu and B. Li, "How green building rating systems affect designing green", Building and Environment, vol. 133, pp. 19-31, 2018. Available: 10.1016/j.buildenv.2018.02.007.

[14]. C. Herrmann, M. Hauschild, T. Gutowski and R. Lifset, "Life Cycle Engineering and SM", Journal of IE, vol. 18, no. 4, pp. 471-477, 2014. Available: $10.1111 /$ jiec. 12177 .

[15]. A. Choi and P. Guda, "Product design enhancement by integration of virtual design and assembly analysis tools", Assembly Automation, vol. 20, no. 4, pp. 283-290, 2000. Available: 10.1108/01445150010378416.

[16]. W. Filho, "Important Prospect: International Workshop on Ecological Education as a Parallel Event to UNCED, to be held in Rio de Janeiro, Brazil, during 4 and 5 June 1992", Ecological Conservation, vol. 19, no. 1, pp. 89-89, 1992. Available: 10.1017/s0376892900030459.

[17]. F. Rauner, "Industrial culture and its implication for a development concept for a "culture of manufacturing"", The International Journal of Advanced Manufacturing Technology, vol. 13, no. 7, pp. 464-473, 1997. Available: 10.1007/bf01624606.

[18]. N. Rashid, J. Jabar, S. Yahya and S. Shami, "Dynamic Eco Innovation Practices: A Systematic Review of State of the Art and Future Direction for Eco Innovation Study", Asian Social Science, vol. 11, no. 1, 2014. Available: 10.5539/ass.v11n1p8. 